\title{
Coupled fixed point results for $(\varphi, G)$-contractions of type (b) in b-metric spaces endowed with a graph
}

\author{
Cristian Chifu*, Gabriela Petruşel \\ Babeş-Bolyai University Cluj-Napoca, Faculty of Business, Cluj-Napoca, Romania.
}

\author{
Communicated by C. Vetro
}

\begin{abstract}
The purpose of this paper is to present some existence results for coupled fixed points of generalized contraction type operators in b-metric spaces endowed with a directed graph. Our results generalize the results obtained by Gnana Bhaskar and Lakshmikantham in [T. Gnana Bhaskar, V. Lakshmikantham, Nonlinear Anal., 65 (2006), 1379-1393]. Data dependence, well-posednes and Ulam-Hyres stability of the fixed point problem are also studied. (C)2017 All rights reserved.
\end{abstract}

Keywords: Fixed point, coupled fixed point, b-metric space, connected graph. 2010 MSC: 47H10, 54H25.

\section{Preliminaries}

In fixed point theory, the importance of study of coupled fixed points is due to their applications to a wide variety of problems. Gnana Bhaskar and Lakshmikantham [8] gave some existence results for coupled fixed point for a mixed monotone type mapping in a metric space endowed with partial order, using a contraction type assumption on the mapping.

The purpose of this paper is to generalize these results using the context of b-metric spaces endowed with a graph. This new research direction in the theory of fixed points was initiated by Jachymski [11], and Gwóźdź-Lukawska and Jachymski [9]. Other results for single-valued and multi-valued operators in such metric spaces were given by Beg et al. in [1], Vetro and Vetro [19], and Chifu and Petrusel in [5].

Our results also generalize and extend some fixed point and coupled fixed point theorems in partially ordered complete metric spaces and b-metric spaces given by Harjani and Sadarangani [10], Nieto and Rodríguez-López [14, 16], Nieto et al. [15], Jleli et al. [13], O’Regan and Petruşel [17], Ran and Reurings [18], Gnana Bhaskar and Lakshmikantham [8], and Chifu and Petrusel in [6].

Let us recall now some essential definitions and fundamental results. We begin with the definition of a b-metric space.

Definition 1.1 ([7]). Let $X$ be a nonempty set and let $s \geqslant 1$ be a given real number. A functional $d$ : $X \times X \rightarrow[0, \infty)$ is said to be a b-metric if the following conditions are satisfied:

\footnotetext{
*Corresponding author

Email addresses: Cristian. Chifu@tbs .ubbcluj.ro (Cristian Chifu), Gabi.Petrusel@tbs .ubbcluj .ro (Gabriela Petruşel)
} 
1. $d(x, y)=0$ if and only if $x=y$;

2. $d(x, y)=d(y, x)$;

3. $d(x, z) \leqslant s[d(x, y)+d(y, z)]$,

for all $x, y, z \in X$. In this case the pair $(X, d)$ is called a $b$-metric space.

Remark 1.2. The class of b-metric spaces is larger than the class of metric spaces since a b-metric space is a metric space when $s=1$. For more details and examples on b-metric spaces, see e.g., [2].

The following example will be useful for our results.

Example 1.3. Let $(X, d)$ be a b-metric space, with constant $\mathrm{s} \geqslant 1$, and let $Z=X \times X$. The functional $\widetilde{\mathrm{d}}: Z \times Z \rightarrow$ $[0, \infty)$, defined by

$$
\widetilde{d}((x, y),(u, v))=d(x, u)+d(y, v),
$$

is a b-metric with the same constant $s \geqslant 1$ for all $(x, y),(u, v) \in Z$. Moreover if $(X, d)$ is a complete b-metric space, then $(Z, \widetilde{d})$ is a complete b-metric space, too.

Definition 1.4. A mapping $\varphi:[0, \infty) \rightarrow[0, \infty)$ is called a comparison function if it increasing and $\varphi^{\mathrm{n}}(\mathrm{t}) \rightarrow 0$ as $\mathrm{n} \rightarrow \infty$ for any $\mathrm{t} \in[0, \infty)$.

We recall the following essential result.

Lemma 1.5 ([4]). If $\varphi:[0, \infty) \rightarrow[0, \infty)$ is a comparison function, then:

(1) each iterate $\varphi^{\mathrm{k}}$ of $\varphi$ (where $\mathrm{k} \geqslant 1$ ) is also a comparison function;

(2) $\varphi$ is continuous at 0 ;

(3) $\varphi(t)<t$ for any $t>0$.

Berinde [4] introduced the concept of (c)-comparison function in the following way.

Definition $1.6([4])$. A function $\varphi:[0, \infty) \rightarrow[0, \infty)$ is said to be a (c)-comparison function if

(1) $\varphi$ is increasing;

(2) there exist $k_{0} \in \mathbb{N}, a \in(0,1)$ and a convergent series of nonnegative terms $\sum_{k=1}^{\infty} v_{k}$ such that $\varphi^{k+1}(t) \leqslant a \varphi^{k}(t)+\nu_{k}$ for $k \geqslant k_{0}$ and any $t \in[0, \infty)$.

The notion of a (c)-comparison function was improved as a (b)-comparison function by Berinde [3], in order to extend some fixed point results to the class of $b$-metric spaces.

Definition 1.7 ([3]). Let $s \geqslant 1$ be a real number. A mapping $\varphi:[0, \infty) \rightarrow[0, \infty)$ is called a (b)-comparison function if the following conditions are fulfilled:

(1) $\varphi$ is monotone increasing;

(2) there exist $k_{0} \in \mathbb{N}, a \in(0,1)$ and a convergent series of nonnegative terms $\sum_{k=1}^{\infty} v_{k}$ such that $s^{k+1} \varphi^{k+1}(t) \leqslant a s^{k} \varphi^{k}(t)+v_{k}$ for $k \geqslant k_{0}$ and any $t \in[0, \infty)$.

It is obvious that the concept of (b)-comparison function reduces to that of (c)-comparison function when $\mathrm{s}=1$.

The following lemma has a crucial role in the proof of our main result.

Lemma 1.8 ([2]). If $\varphi:[0, \infty) \rightarrow[0, \infty)$ is a (b)-comparison function, then we have the following:

(1) the series $\sum_{k=0}^{\infty} s^{k} \varphi^{k}(t)$ converges for any $t \in[0, \infty)$; 
(2) the function $\mathrm{S}_{\mathrm{b}}:[0, \infty) \rightarrow[0, \infty)$ defined by $\mathrm{S}_{\mathrm{b}}(\mathrm{t})=\sum_{\mathrm{k}=0}^{\infty} \mathrm{s}^{\mathrm{k}} \varphi^{\mathrm{k}}(\mathrm{t}), \mathrm{t} \in[0, \infty)$, is increasing and continuous at 0 .

We note that any (b)-comparison function is a comparison function due to the above lemma.

Let $(X, d)$ be a metric space and $\Delta$ be the diagonal of $X \times X$. Let $G$ be a directed graph, such that the set $V(G)$ of its vertices coincides with $X$ and $\Delta \subseteq E(G)$, where $E(G)$ is the set of the edges of the graph. Assume also that $G$ has no parallel edges and, thus, one can identify $G$ with the pair $(V(G), E(G)$ ).

Throughout the paper we shall say that $G$ with the above mentioned properties satisfies standard conditions.

Let $\mathrm{us}$ denote by $\mathrm{G}^{-1}$ the graph obtained from $\mathrm{G}$ by reversing the direction of edges. Thus,

$$
E\left(G^{-1}\right)=\{(x, y) \in X \times X:(y, x) \in E(G)\} .
$$

Let us consider the function $\mathrm{F}: \mathrm{X} \times \mathrm{X} \rightarrow \mathrm{X}$.

Definition 1.9. An element $(x, y) \in X \times X$ is called coupled fixed point of the mapping $F$, if $F(x, y)=x$ and $F(y, x)=y$.

We shall denote by $\mathrm{CFix}(\mathrm{F})$ the set of all coupled fixed points of mapping $F$, i.e.,

$$
\operatorname{CFix}(F)=\{(x, y) \in X \times X: F(x, y)=x \text { and } F(y, x)=y\} .
$$

Definition 1.10 ([6]). We say that $F: X \times X \rightarrow X$ is edge preserving if

$$
(x, u) \in E(G) \text { and }(y, v) \in E\left(G^{-1}\right) \Rightarrow(F(x, y), F(u, v)) \in E(G)
$$

and

$$
(F(y, x), F(v, u)) \in E\left(G^{-1}\right) .
$$

Definition 1.11 ([6]). The operator $F: X \times X \rightarrow X$ is called G-continuous if for all $(x, y) \in X \times X,\left(x^{*}, y^{*}\right) \in$ $X \times X$ and for any sequence $\left(n_{i}\right)_{i \in \mathbb{N}}$ of positive integers, with $F^{n_{i}}(x, y) \rightarrow x^{*}, F^{n_{i}}(y, x) \rightarrow y^{*}$, as $i \rightarrow \infty$, and $\left(F^{n_{i}}(x, y), F^{n_{i}+1}(x, y)\right) \in E(G),\left(F^{n_{i}}(y, x), F^{n_{i}+1}(y, x)\right) \in E\left(G^{-1}\right)$, we have that

$$
\begin{aligned}
& F\left(F^{n_{i}}(x, y), F^{n_{i}}(y, x)\right) \rightarrow F\left(x^{*}, y^{*}\right) \\
& F\left(F^{n_{i}}(y, x), F^{n_{i}}(x, y)\right) \rightarrow F\left(y^{*}, x^{*}\right)
\end{aligned}, \text { as } i \rightarrow \infty
$$

Definition $1.12([6])$. Let $(X, d)$ be a b-metric space, with constant $s \geqslant 1$, and $G$ be a directed graph. We say that the triple $(X, d, G)$ has the property $\left(A_{1}\right)$, if for any sequence $\left(x_{n}\right)_{n \in \mathbb{N}} \subset X$ with $x_{n} \rightarrow x$, as $n \rightarrow \infty$, and $\left(x_{n}, x_{n+1}\right) \in E(G)$, for $n \in \mathbb{N}$, we have that $\left(x_{n}, x\right) \in E(G)$.

Definition $1.13([6])$. Let $(X, d)$ be a b-metric space, with constant $s \geqslant 1$, and $G$ be a directed graph. We say that the triple $(X, d, G)$ has the property $\left(A_{2}\right)$, if for any sequence $\left(x_{n}\right)_{n \in \mathbb{N}} \subset X$ with $x_{n} \rightarrow x$, as $n \rightarrow \infty$, and $\left(x_{n}, x_{n+1}\right) \in E\left(G^{-1}\right)$, for $n \in \mathbb{N}$, we have that $\left(x_{n}, x\right) \in E\left(G^{-1}\right)$.

\section{Existence and data dependence results for coupled fixed point problems}

Let $(X, d)$ be a $b$-metric space, with constant $s \geqslant 1$, endowed with a directed graph $G$ satisfying the standard conditions. We consider the set denoted by $(X \times X)^{F}$ and defined as:

$$
(X \times X)^{F}=\left\{(x, y) \in X \times X:(x, F(x, y)) \in E(G) \text { and }(y, F(y, x)) \in E\left(G^{-1}\right)\right\} .
$$

Proposition 2.1 ([6]). If $\mathrm{F}: \mathrm{X} \times \mathrm{X} \rightarrow \mathrm{X}$ is edge preserving, then:

(i) $(x, u) \in E(G)$ and $(y, v) \in E\left(G^{-1}\right)$ implies $\left(F^{n}(x, y), F^{n}(u, v)\right) \in E(G)$ and $\left(F^{n}(y, x), F^{n}(v, u)\right) \in$ $\mathrm{E}\left(\mathrm{G}^{-1}\right)$ for all $\mathrm{n} \in \mathbb{N}$; 
(ii) $(x, y) \in(X \times X)^{F}$ implies $\left(F^{n}(x, y), F^{n+1}(x, y)\right) \in E(G)$ and $\left(F^{n}(y, x), F^{n+1}(y, x)\right) \in E\left(G^{-1}\right)$ for all $\mathrm{n} \in \mathbb{N}$

(iii) $(x, y) \in(X \times X)^{F}$ implies $\left(F^{n}(x, y), F^{n}(y, x)\right) \in(X \times X)^{F}$ for all $n \in \mathbb{N}$.

Definition 2.2. The mapping $F: X \times X \rightarrow X$ is called $(\varphi, G)$-contraction of type $(b)$ if:

(i) $\mathrm{F}$ is edge preserving;

(ii) there exists $\varphi:[0, \infty) \rightarrow[0, \infty)$ a (b)-comparison function such that

$$
\begin{gathered}
d(F(x, y), F(u, v))+d(F(y, x), F(v, u)) \leqslant \varphi(d(x, u)+d(y, v)), \\
\text { for all }(x, u) \in E(G),(y, v) \in E\left(G^{-1}\right) .
\end{gathered}
$$

Lemma 2.3. Let $(\mathrm{X}, \mathrm{d})$ be a b-metric space, with constant $\mathrm{s} \geqslant 1$, endowed with a directed graph $\mathrm{G}$ and let $\mathrm{F}: \mathrm{X} \times \mathrm{X} \rightarrow \mathrm{X}$ be $a(\varphi, \mathrm{G})$-contraction of type $(\mathrm{b})$. Then,

$$
d\left(F^{n}(x, y), F^{n}(u, v)\right)+d\left(F^{n}(y, x), F^{n}(v, u)\right) \leqslant \varphi^{n}(d(x, u)+d(y, v)),
$$

for all $(x, u) \in E(G),(y, v) \in E\left(G^{-1}\right), n \in \mathbb{N}$.

Proof. Let $(x, u) \in E(G),(y, v) \in E\left(G^{-1}\right)$. Because $F$ is edge preserving we have

$$
(F(x, y), F(u, v)) \in E(G) \text { and }(F(y, x), F(v, u)) \in E\left(G^{-1}\right) \text {. }
$$

From Proposition 2.1 (i) it follows that

$$
\left(F^{n}(x, y), F^{n}(u, v)\right) \in E(G) \text { and }\left(F^{n}(y, x), F^{n}(v, u)\right) \in E\left(G^{-1}\right) .
$$

Since $F$ is a $(\varphi, G)$-contraction of type $(b)$, we obtain

$$
\begin{aligned}
d\left(F^{2}(x, y), F^{2}(u, v)\right)+d\left(F^{2}(y, x), F^{2}(v, u)\right)= & d(F(F(x, y), F(y, x)), F(F(u, v), F(v, u))) \\
& +d(F(F(y, x), F(x, y)), F(F(v, u), F(u, v))) \\
& \leqslant \varphi(d(F(x, y), F(u, v))+d(F(y, x), F(v, u))) \\
& \leqslant \varphi(\varphi(d(x, u)+d(y, v))) \\
& \leqslant \varphi^{2}(d(x, u)+d(y, v)) .
\end{aligned}
$$

Hence, by induction, we reach the conclusion.

Lemma 2.4. Let $(\mathrm{X}, \mathrm{d})$ be a b-metric space, with constant $\mathrm{s} \geqslant 1$, endowed with a directed graph $\mathrm{G}$ and let $\mathrm{F}: \mathrm{X} \times \mathrm{X} \rightarrow \mathrm{X}$ be $a(\varphi, \mathrm{G})$-contraction of type $(\mathrm{b})$. Then, given $(\mathrm{x}, \mathrm{y}) \in(\mathrm{X} \times \mathrm{X})^{\mathrm{F}}$, there exists $\mathrm{r}(\mathrm{x}, \mathrm{y}) \geqslant 0$ such that

$$
d\left(F^{n}(x, y), F^{n+1}(x, y)\right)+d\left(F^{n}(y, x), F^{n+1}(y, x)\right) \leqslant \varphi^{n}(r(x, y)) \text { for all } n \in \mathbb{N} \text {. }
$$

Proof. Let $(x, y) \in(X \times X)^{F}$. It follows that $(x, F(x, y)) \in E(G)$ and $(y, F(y, x)) \in E\left(G^{-1}\right)$.

If in Lemma 2.3 we consider $u=F(x, y)$ and $v=F(y, x)$ we shall obtain

$$
\begin{gathered}
d\left(F^{n}(x, y), F^{n}(F(x, y), F(y, x))\right)+d\left(F^{n}(y, x), F^{n}(F(y, x), F(x, y))\right) \\
\leqslant \varphi^{n}(d(x, F(x, y))+d(y, F(y, x))) \text { for all } n \in \mathbb{N},
\end{gathered}
$$

which is

$$
d\left(F^{n}(x, y), F^{n+1}(x, y)\right)+d\left(F^{n}(y, x), F^{n+1}(y, x)\right) \leqslant \varphi^{n}(d(x, F(x, y))+d(y, F(y, x))) \text { for all } n \in \mathbb{N} .
$$

If we consider $r(x, y):=d(x, F(x, y))+d(y, F(y, x))$, then

$$
d\left(F^{n}(x, y), F^{n+1}(x, y)\right)+d\left(F^{n}(y, x), F^{n+1}(y, x)\right) \leqslant \varphi^{n}(r(x, y)) \text { for all } n \in \mathbb{N} \text {. }
$$


Lemma 2.5. Let $(\mathrm{X}, \mathrm{d})$ be a complete b-metric space with constant $\mathrm{s} \geqslant 1$, endowed with a directed graph $\mathrm{G}$ and let $\mathrm{F}: \mathrm{X} \times \mathrm{X} \rightarrow \mathrm{X}$ be $a(\varphi, \mathrm{G})$-contraction of type $(\mathrm{b})$. Then for each $(\mathrm{x}, \mathrm{y}) \in(\mathrm{X} \times \mathrm{X})^{\mathrm{F}}$, there exist $\mathrm{x}^{*}(\mathrm{x}) \in \mathrm{X}$ and $\mathrm{y}^{*}(\mathrm{y}) \in \mathrm{X}$ such that $\left(\mathrm{F}^{\mathrm{n}}(\mathrm{x}, \mathrm{y})\right)_{\mathrm{n} \in \mathbb{N}}$ converges to $\mathrm{x}^{*}(\mathrm{x})$ and $\left(\mathrm{F}^{\mathrm{n}}(\mathrm{y}, \mathrm{x})\right)_{\mathrm{n} \in \mathbb{N}}$ converges to $\mathrm{y}^{*}(\mathrm{y})$, as $\mathrm{n} \rightarrow \infty$.

Proof. Let $(x, y) \in(X \times X)^{F}$. It follows that $(x, F(x, y)) \in E(G)$ and $(y, F(y, x)) \in E\left(G^{-1}\right)$. Let $Z=X \times X$ and consider the b-metric given by Example 1.3, $\widetilde{\mathrm{d}}: \mathrm{Z} \times \mathrm{Z} \rightarrow[0, \infty)$, defined by

$$
\widetilde{d}((x, y),(u, v))=d(x, u)+d(y, v) \text { for all }(x, y),(u, v) \in Z \text {. }
$$

Consider also, the operator $\mathrm{T}: \mathrm{Z} \rightarrow \mathrm{Z}$, defined by

$$
T(x, y)=(F(x, y), F(y, x)) \text { for all }(x, y) \in Z \text {. }
$$

For $(x, y)$ and $(u, v) \in(X \times X)^{\mathrm{F}}$, we have

$$
\widetilde{d}(T(x, y), T(u, v))=d(F(x, y), F(u, v))+d(F(y, x), F(v, u)) .
$$

If $u=F(x, y)$ and $v=F(y, x)$, then $(u, v) \in(X \times X)^{F}$ and $T(u, v)=T^{2}(x, y)$. Hence

$$
\widetilde{d}\left(T(x, y), T^{2}(x, y)\right)=d\left(F(x, y), F^{2}(x, y)\right)+d\left(F(y, x), F^{2}(y, x)\right) .
$$

By induction we shall obtain

$$
\widetilde{d}\left(T^{n}(x, y), T^{n+1}(x, y)\right)=d\left(F^{n}(x, y), F^{n+1}(x, y)\right)+d\left(F^{n}(y, x), F^{n+1}(y, x)\right) .
$$

From Lemma 2.4, we have

$$
\widetilde{\mathrm{d}}\left(T^{n}(x, y), T^{n+1}(x, y)\right) \leqslant \varphi^{n}(r(x, y)) \text { for all } n \in \mathbb{N} .
$$

Now we shall prove that $\left(T^{n}(x, y)\right)_{\mathfrak{n} \in \mathbb{N}}$ is a Cauchy sequence. We have

$$
\begin{aligned}
\widetilde{\mathrm{d}}\left(T^{n}(x, y), T^{n+p}(x, y)\right) \leqslant & s \widetilde{d}\left(T^{n}(x, y), T^{n+1}(x, y)\right)+s^{2} \widetilde{d}\left(T^{n+1}(x, y), T^{n+2}(x, y)\right) \\
& +\cdots+s^{p-1} \widetilde{d}\left(T^{n+p-2}(x, y), T^{n+p-1}(x, y)\right) \\
& +s^{p} \widetilde{d}\left(T^{n+p-1}(x, y), T^{n+p}(x, y)\right) \\
\leqslant & s \varphi^{n}(r(x, y))+s^{2} \varphi^{n+1}(r(x, y))+\ldots+s^{p-1} \varphi^{n+p-2}(r(x, y)) \\
& +s^{p} \varphi^{n+p-1}(r(x, y)) \\
= & \frac{1}{s^{n-1}} \sum_{k=n}^{n+p-1} s^{k} \varphi^{k}(r(x, y)) .
\end{aligned}
$$

Let $S_{n}=\sum_{k=0}^{n} s^{k} \varphi^{k}(r(x, y))$. Hence we have

$$
\widetilde{d}\left(T^{n}(x, y), T^{n+p}(x, y)\right) \leqslant \frac{1}{s^{n-1}}\left(S_{n+p-1}-S_{n-1}\right) \leqslant \frac{1}{s^{n-1}} \sum_{k=0}^{\infty} s^{k} \varphi^{k}(r(x, y)) .
$$

From Lemma 1.8 we have that the series is convergent. In this way, we shall obtain

$$
\widetilde{\mathrm{d}}\left(T^{n}(x, y), T^{n+p}(x, y)\right) \leqslant \frac{1}{s^{n-1}} \sum_{k=0}^{\infty} s^{k} \varphi^{k}(r(x, y)) \rightarrow 0 \text {, as } n \rightarrow \infty .
$$

In conclusion the sequence $\left(T^{n}(x, y)\right)_{n \in \mathbb{N}}$ is a Cauchy sequence.

Since $(X, d)$ is a complete b-metric space, from Example 1.3, we have that $(Z, \widetilde{d})$ is a complete b-metric space, and hence there exists $\left(x^{*}(x), y^{*}(y)\right) \in X \times X$ such that $T^{n}(x, y) \rightarrow\left(x^{*}(x), y^{*}(y)\right)$, as $n \rightarrow \infty$. This is equivalent to $\left(F^{n}(x, y), F^{n}(y, x)\right) \rightarrow\left(x^{*}(x), y^{*}(y)\right)$, as $n \rightarrow \infty$.

Hence, there exist $x^{*}(x) \in X$ and $y^{*}(y) \in X$ such that $\left(F^{n}(x, y)\right)_{n \in \mathbb{N}}$ and $\left(F^{n}(y, x)\right)_{n \in \mathbb{N}}$ converge to $x^{*}(x)$ and $y^{*}(y)$, respectively, as $n \rightarrow \infty$. 
Now we shall prove the main results of this section.

Theorem 2.6. Let $(\mathrm{X}, \mathrm{d})$ be a complete b-metric space with constant $\mathrm{s} \geqslant 1$, endowed with a directed graph $\mathrm{G}$ and let $\mathrm{F}: \mathrm{X} \times \mathrm{X} \rightarrow \mathrm{X}$ be $a(\varphi, \mathrm{G})$-contraction of type $(\mathrm{b})$. Suppose that:

(i) $F$ is G-continuous; or

(ii) the triple $(X, d, G)$ has the properties $\left(A_{1}\right)$ and $\left(A_{2}\right)$.

In these conditions $\mathrm{CFix}(\mathrm{F}) \neq \varnothing$ if and only if $(\mathrm{X} \times \mathrm{X})^{\mathrm{F}} \neq \varnothing$.

Proof. Suppose that $\mathrm{CFix}(\mathrm{F}) \neq \varnothing$. Let $\left(x^{*}, \mathrm{y}^{*}\right) \in \mathrm{CFix}(\mathrm{F})$. We have $\left(x^{*}, \mathrm{~F}\left(x^{*}, \mathrm{y}^{*}\right)\right)=\left(x^{*}, x^{*}\right) \in \Delta \subset \mathrm{E}(\mathrm{G})$ and $\left(y^{*}, F\left(y^{*}, x^{*}\right)\right)=\left(y^{*}, y^{*}\right) \in \Delta \subset E\left(G^{-1}\right)$.

Hence $\left(x^{*}, F\left(x^{*}, y^{*}\right)\right) \in E(G)$ and $\left(y^{*}, F\left(y^{*}, x^{*}\right)\right) \in E\left(G^{-1}\right)$ which means that $\left(x^{*}, y^{*}\right) \in(X \times X)^{F}$ and thus $(\mathrm{X} \times \mathrm{X})^{\mathrm{F}} \neq \varnothing$.

Suppose now that $(X \times X)^{F} \neq \varnothing$. Let $(x, y) \in(X \times X)^{F}$. It follows that $(x, F(x, y)) \in E(G)$ and $(y, F(y, x)) \in E\left(G^{-1}\right)$.

Let $\left(n_{i}\right)_{i \in \mathbb{N}}$ be a sequence of positive integers. From Proposition 2.1 (ii), we know that

$$
\begin{aligned}
& \left(F^{n_{i}}(x, y), F^{n_{i}+1}(x, y)\right) \in E(G) \\
& \left(F^{n_{i}}(y, x), F^{n_{i}+1}(y, x)\right) \in E\left(G^{-1}\right) .
\end{aligned}
$$

Moreover from Lemma 2.5, there exist $x^{*}(x) \in X$ and $y^{*}(y) \in X$ such that

$$
\begin{aligned}
\mathrm{cF}^{\mathrm{n}_{i}}(x, y) & \rightarrow x^{*}(x), \text { as } i \rightarrow \infty . \\
\mathrm{F}^{\mathrm{n}_{i}}(y, x) & \rightarrow y^{*}(y),
\end{aligned}
$$

We shall prove that $F\left(x^{*}, y^{*}\right)=x^{*}$ and $F\left(y^{*}, x^{*}\right)=y^{*}$. Suppose that (i) takes place. Since $F$ is Gcontinuous we shall obtain that

$$
\begin{aligned}
\operatorname{cF}\left(F^{n_{i}}(x, y), F^{n_{i}}(y, x)\right) & \rightarrow F\left(x^{*}, y^{*}\right), \\
F\left(F^{n_{i}}(y, x), F^{n_{i}}(x, y)\right) & \rightarrow F\left(y^{*}, x^{*}\right),
\end{aligned}
$$

Now

$$
\begin{aligned}
d\left(F\left(x^{*}, y^{*}\right), x^{*}\right)+d\left(F\left(y^{*}, x^{*}\right), y^{*}\right) \leqslant & s\left[d\left(F\left(x^{*}, y^{*}\right), F^{n_{i}+1}(x, y)\right)+d\left(F^{n_{i}+1}(x, y), x^{*}\right)\right] \\
& +s\left[d\left(F\left(y^{*}, x^{*}\right), F^{n_{i}+1}(y, x)\right)+d\left(F^{n_{i}+1}(y, x), y^{*}\right)\right] .
\end{aligned}
$$

Using the G-continuity of $F$ and the convergence of $\left(F^{n}(x, y)\right)_{n \in \mathbb{N}^{\prime}}$, we obtain that $d\left(F\left(x^{*}, y^{*}\right), x^{*}\right)+$ $d\left(F\left(y^{*}, x^{*}\right), y^{*}\right)=0$, i.e., $F\left(x^{*}, y^{*}\right)=x^{*}$ and $F\left(y^{*}, x^{*}\right)=y^{*}$.

Thus $\left(x^{*}, y^{*}\right)$ is a coupled fixed point of the mapping $F$, so $C F i x(F) \neq \varnothing$.

Suppose now that (ii) takes place. From (2.1) and (2.2), using properties $\left(A_{1}\right)$ and $\left(A_{2}\right)$ of the triple $(X, d, G)$, we shall obtain that

$$
\left(F^{n}(x, y), x^{*}\right) \in E(G), \quad\left(F^{n}(y, x), y^{*}\right) \in E\left(G^{-1}\right) .
$$

We have

$$
\begin{aligned}
d\left(F\left(x^{*}, y^{*}\right), x^{*}\right)+d\left(F\left(y^{*}, x^{*}\right), y^{*}\right) \leqslant & s\left[d\left(F^{n+1}(x, y), F\left(x^{*}, y^{*}\right)\right)+d\left(F^{n+1}(x, y), x^{*}\right)\right] \\
& +s\left[d\left(F^{n+1}(y, x), F\left(y^{*}, x^{*}\right)\right)+d\left(F^{n+1}(y, x), y^{*}\right)\right] \\
= & s\left[d\left(F\left(F^{n}(x, y), F^{n}(y, x)\right), F\left(x^{*}, y^{*}\right)\right)+d\left(F^{n+1}(x, y), x^{*}\right)\right] \\
& +s\left[d\left(F^{n}\left(F^{n}(y, x), F^{n}(x, y)\right), F\left(y^{*}, x^{*}\right)\right)+d\left(F^{n+1}(y, x), y^{*}\right)\right] \\
\leqslant & s \varphi\left(d\left(F^{n}(x, y), x^{*}\right)+d\left(F^{n}(y, x), y^{*}\right)\right)+s d\left(F^{n+1}(x, y), x^{*}\right) \\
& +s d\left(F^{n+1}(y, x), y^{*}\right) \rightarrow 0, \text { as } n \rightarrow \infty .
\end{aligned}
$$

Hence $d\left(F\left(x^{*}, y^{*}\right), x^{*}\right)+d\left(F\left(y^{*}, x^{*}\right), y^{*}\right)=0$, which means that $F\left(x^{*}, y^{*}\right)=x^{*}$ and $F\left(y^{*}, x^{*}\right)=y^{*}$. Thus, $\left(x^{*}, y^{*}\right) \in \operatorname{CFix}(F)$. 
Let us suppose now that for every $(x, y),(u, v) \in X \times X$, there exists $(z, w) \in X \times X$ such that

$$
(x, z) \in E(G),(y, w) \in E\left(G^{-1}\right), \quad(u, z) \in E(G),(v, w) \in E\left(G^{-1}\right) .
$$

Theorem 2.7. Adding condition (2.3) to the hypotheses of Theorem 2.6 we obtain the uniqueness of the coupled fixed point of $F$.

Proof. Let us suppose that there exist $\left(x^{*}, y^{*}\right),\left(u^{*}, v^{*}\right) \in X \times X$ two coupled fixed points of F. From (2.3) we have that there exists $(z, w) \in X \times X$ such that

$$
\left(x^{*}, z\right) \in E(G),\left(y^{*}, w\right) \in E\left(G^{-1}\right), \quad\left(u^{*}, z\right) \in E(G),\left(v^{*}, w\right) \in E\left(G^{-1}\right) .
$$

Using Lemma 2.3, we shall have

$$
\begin{aligned}
d\left(x^{*}, u^{*}\right)+d\left(y^{*}, v^{*}\right)= & d\left(F^{n}\left(x^{*}, y^{*}\right), F^{n}\left(u^{*}, v^{*}\right)\right)+d\left(F^{n}\left(y^{*}, x^{*}\right), F^{n}\left(v^{*}, u^{*}\right)\right) \\
\leqslant & s\left[d\left(F^{n}\left(x^{*}, y^{*}\right), F^{n}(z, w)\right)+d\left(F^{n}(z, w), F^{n}\left(u^{*}, v^{*}\right)\right)\right] \\
& +s\left[d\left(F^{n}\left(y^{*}, x^{*}\right), F^{n}(w, z)\right)+d\left(F^{n}(w, z), F^{n}\left(v^{*}, u^{*}\right)\right)\right] \\
\leqslant & \left.\varphi^{n}\left(d\left(x^{*}, z\right)+d\left(y^{*}, w\right)\right)+\varphi^{n}\left(d\left(u^{*}, z\right)+d\left(v^{*}, w\right)\right)\right) \rightarrow 0, \text { as } n \rightarrow \infty .
\end{aligned}
$$

Hence $d\left(x^{*}, u^{*}\right)+d\left(y^{*}, v^{*}\right)=0$ and thus we obtain that $x^{*}=u^{*}$ and $y^{*}=v^{*}$.

Remark 2.8. It is obvious that if $\left(x^{*}, \mathrm{u}^{*}\right) \in \mathrm{E}(\mathrm{G})$ and $\left(\mathrm{y}^{*}, v^{*}\right) \in \mathrm{E}\left(\mathrm{G}^{-1}\right)$, then $x^{*}=\mathrm{u}^{*}$ and $\mathrm{y}^{*}=v^{*}$.

Theorem 2.9. In the conditions of Theorem 2.6, if $\left(x^{*}, y^{*}\right) \in \operatorname{CFix}(F)$ with $\left(x^{*}, y^{*}\right) \in E(G)$, then $x^{*}=y^{*}$.

Proof. Since $\left(x^{*}, y^{*}\right) \in E(G)$, then $\left(y^{*}, x^{*}\right) \in E\left(G^{-1}\right)$. By the fact that $F$ is a $(\varphi, G)$-contraction of type (b), we have

$$
\begin{aligned}
2 d\left(x^{*}, y^{*}\right) & =d\left(F\left(x^{*}, y^{*}\right), F\left(y^{*}, x^{*}\right)\right)+d\left(F\left(y^{*}, x^{*}\right), F\left(x^{*}, y^{*}\right)\right) \\
& \leqslant \varphi\left(d\left(x^{*}, y^{*}\right)+d\left(y^{*}, x^{*}\right)\right)=\varphi\left(2 d\left(x^{*}, y^{*}\right)\right)
\end{aligned}
$$

From the properties of $\varphi$, we obtain that $d\left(x^{*}, y^{*}\right)=0$ and thus $x^{*}=y^{*}$.

Remark 2.10. It is obvious that if we consider a function $f: X \rightarrow X, f(x)=F(x, x)$ all these results concerning the coupled fixed point of the mapping $F$ result in the existence and uniqueness results for the fixed point of $f$.

In what follows we shall give a data-dependence result.

Theorem 2.11 (data dependence). Let $(\mathrm{X}, \mathrm{d})$ be a complete b-metric space with constant $\mathrm{s} \geqslant 1$, endowed with a directed graph $\mathrm{G}$ and let $\mathrm{F}_{\mathrm{i}}: \mathrm{X} \times \mathrm{X} \rightarrow \mathrm{X}, \mathrm{i} \in\{1,2\}$ be two mappings. Assume that the following conditions are satisfied:

(i) $F_{1}$ is a $(\varphi, \mathrm{G})$-contraction of type (b);

(ii) $F_{1}$ is G-continuous;

or

(ii*) the triple $(X, d, G)$ has the properties $\left(A_{1}\right)$ and $\left(A_{2}\right)$;

(iii) for every $(x, y),(u, v) \in X \times X$, there exists $(z, w) \in X \times X$ such (2.3) holds;

(iv) $\mathrm{CFix}\left(\mathrm{F}_{2}\right) \neq \varnothing$;

(v) there exists $\eta>0$ such that

$d\left(F_{1}(x, y), F_{2}(x, y)\right) \leqslant \eta, \forall(x, y) \in X \times X$ 
In these conditions, if $\left(x^{*}, y^{*}\right)$ denotes the unique coupled fixed point of $\mathrm{F}_{1}$, then

$$
\begin{aligned}
d\left(x^{*}, \bar{x}\right)+d\left(y^{*}, \bar{y}\right) & \leqslant \sup \left\{t \in \mathbb{R}_{+} \mid t-s \varphi(t) \leqslant 2 s \eta\right\}, \\
\forall(\bar{x}, \bar{y}) & \in \operatorname{CFix}\left(F_{2}\right) \text { and }\left(x^{*}, \bar{x}\right) \in E(G),\left(y^{*}, \bar{y}\right) \in E\left(G^{-1}\right) .
\end{aligned}
$$

Proof. Let $\left(x^{*}, y^{*}\right) \in X \times X$ be the unique coupled fixed point of $F_{1}$. It follows that

$$
\left\{\begin{array}{l}
x^{*}=F_{1}\left(x^{*}, y^{*}\right), \\
y^{*}=F_{1}\left(y^{*}, x^{*}\right) .
\end{array}\right.
$$

Since $C$ Fix $\left(F_{2}\right) \neq \varnothing$, let $(\bar{x}, \bar{y}) \in C$ Fix $\left(F_{2}\right)$ with $\left(x^{*}, \bar{x}\right) \in E(G),\left(y^{*}, \bar{y}\right) E\left(G^{-1}\right)$. Let $Z=X \times X$ and consider the functional $\widetilde{\mathrm{d}}: Z \times Z \rightarrow[0, \infty)$ defined by

$$
\widetilde{d}((x, y),(u, v))=d(x, u)+d(y, v) \text { for all }(x, y),(u, v) \in Z \text {. }
$$

We have

$$
\begin{aligned}
\widetilde{d}\left(\left(x^{*}, y^{*}\right),(\bar{x}, \bar{y})\right)= & \widetilde{d}\left(\left(F_{1}\left(x^{*}, y^{*}\right), F_{1}\left(y^{*}, x^{*}\right)\right),\left(F_{2}(\bar{x}, \bar{y}), F_{2}(\bar{y}, \bar{x})\right)\right) \\
= & d\left(F_{1}\left(x^{*}, y^{*}\right), F_{2}(\bar{x}, \bar{y})\right)+d\left(F_{1}\left(y^{*}, x^{*}\right), F_{2}(\bar{y}, \bar{x})\right) \\
\leqslant & s\left[d\left(F_{1}\left(x^{*}, y^{*}\right), F_{1}(\bar{x}, \bar{y})\right)+d\left(F_{1}(\bar{x}, \bar{y}), F_{2}(\bar{x}, \bar{y})\right)\right] \\
& +s\left[d\left(F_{1}\left(y^{*}, x^{*}\right), F_{1}(\bar{y}, \bar{x})\right)+d\left(F_{1}(\bar{y}, \bar{x}), F_{2}(\bar{y}, \bar{x})\right)\right] \\
\leqslant & s \varphi\left(d\left(x^{*}, \bar{x}\right)+d\left(y^{*}, \bar{y}\right)\right)+2 s \eta .
\end{aligned}
$$

Hence $d\left(x^{*}, \bar{x}\right)+d\left(y^{*}, \bar{y}\right) \leqslant \sup \left\{t \in \mathbb{R}_{+} \mid t-s \varphi(t) \leqslant 2 s \eta\right\}, \forall\left(x^{*}, y^{*}\right) \in \operatorname{CFix}\left(F_{1}\right)$ and $(\bar{x}, \bar{y}) \in \operatorname{CFix}\left(F_{2}\right)$.

Remark 2.12. In the light of the recent approach in [12], it is an open question to give similar results in the context of K-metric spaces.

\section{Well-posedness and Ulam-Hyers stability}

Let $\mathrm{F}: \mathrm{X} \times \mathrm{X} \rightarrow \mathrm{X}$. Consider now the following coupled fixed point problem

$$
\left\{\begin{array}{l}
x=F(x, y), \\
y=F(y, x),
\end{array}\right.
$$

Definition 3.1. Let $(X, d)$ be a complete b-metric space with constant $s \geqslant 1$. By definition, the coupled fixed point problem (P1) is said to be well-posed if:

(i) $\operatorname{CFix}(F)=\left\{\left(x^{*}, y^{*}\right)\right\}$;

(ii) for any sequence $\left(x_{n}, y_{n}\right)_{n \in \mathbb{N}}$ in $X \times X$ for which $d\left(x_{n}, F\left(x_{n}, y_{n}\right)\right) \rightarrow 0$ and respectively $d\left(y_{n}, F\left(y_{n}\right.\right.$, $\left.\left.x_{n}\right)\right) \rightarrow 0$ as $n \rightarrow \infty$, we have that $x_{n} \rightarrow x^{*}$ and $y_{n} \rightarrow y^{*}$, as $n \rightarrow \infty$.

Theorem 3.2. Suppose that the operator $\mathrm{F}: \mathrm{X} \times \mathrm{X} \rightarrow \mathrm{X}$ verifies all hypotheses of Theorem 2.7 and for any sequence $\left(x_{n}, y_{n}\right)_{n \in \mathbb{N}}$ in $\mathrm{X} \times X$ having property that $\mathrm{d}\left(\mathrm{x}_{\mathrm{n}}, \mathrm{F}\left(\mathrm{x}_{\mathrm{n}}, \mathrm{y}_{\mathrm{n}}\right)\right) \rightarrow 0$ and respectively $\mathrm{d}\left(\mathrm{y}_{\mathrm{n}}, \mathrm{F}\left(\mathrm{y}_{\mathrm{n}}, \mathrm{x}_{\mathrm{n}}\right)\right) \rightarrow 0$ as $\mathrm{n} \rightarrow \infty$, we have $\left(\mathrm{x}_{\mathrm{n}}, \mathrm{x}^{*}\right) \in \mathrm{E}(\mathrm{G})$ and $\left(\mathrm{y}_{\mathrm{n}}, \mathrm{y}^{*}\right) \in \mathrm{E}\left(\mathrm{G}^{-1}\right)$. If the mapping $\psi:[0, \infty) \rightarrow \mathbb{R}, \psi(\mathrm{t})=\mathrm{t}-\mathrm{s} \varphi(\mathrm{t})$, is such that $\psi(\mathrm{t}) \geqslant 0, \forall \mathrm{t} \in \mathbb{R}_{+}$and $\psi(0)=0$ implies that $\mathrm{t}=0$, then the coupled fixed point problem (P1) is well-posed.

Proof. By Theorem 2.7, it follows that the coupled fixed point problem (P1) has a unique solution $\left(x^{*}, y^{*}\right)$, i.e., $\operatorname{CFix}(F)=\left\{\left(x^{*}, y^{*}\right)\right\}$.

Let $\left(x_{n}, y_{n}\right)_{n \in \mathbb{N}} \subset X \times X$ be a sequence which verifies the following properties: 
(a) $d\left(x_{n}, F\left(x_{n}, y_{n}\right)\right) \rightarrow 0$ and respectively $d\left(y_{n}, F\left(y_{n}, x_{n}\right)\right) \rightarrow 0$ as $n \rightarrow \infty$;

(b) $\left(x_{n}, x^{*}\right) \in E(G)$ and $\left(y_{n}, y^{*}\right) \in E\left(G^{-1}\right)$.

Let $Z=X \times X$ and consider the functional $\widetilde{d}: Z \times Z \rightarrow[0, \infty)$ defined by

$$
\tilde{d}((x, y),(u, v))=d(x, u)+d(y, v) \text { for all }(x, y),(u, v) \in Z \text {. }
$$

We have

$$
\begin{aligned}
\widetilde{d}\left(\left(x_{n}, y_{n}\right),\left(x^{*}, y^{*}\right)\right)= & \widetilde{d}\left(\left(x_{n}, y_{n}\right),\left(F\left(x^{*}, y^{*}\right), F\left(y^{*}, x^{*}\right)\right)\right) \\
\leqslant & s \widetilde{d}\left(\left(x_{n}, y_{n}\right),\left(F\left(x_{n}, y_{n}\right), F\left(y_{n}, x_{n}\right)\right)\right) \\
& +s \widetilde{d}\left(\left(F\left(x_{n}, y_{n}\right), F\left(y_{n}, x_{n}\right)\right),\left(F\left(x^{*}, y^{*}\right), F\left(y^{*}, x^{*}\right)\right)\right) \\
\leqslant & s \widetilde{d}\left(\left(x_{n}, y_{n}\right),\left(F\left(x_{n}, y_{n}\right), F\left(y_{n}, x_{n}\right)\right)\right)+s \varphi\left(\widetilde{d}\left(\left(x_{n}, y_{n}\right),\left(x^{*}, y^{*}\right)\right)\right) .
\end{aligned}
$$

Hence

$$
\widetilde{d}\left(\left(x_{n}, y_{n}\right),\left(x^{*}, y^{*}\right)\right)-s \varphi\left(\widetilde{d}\left(\left(x_{n}, y_{n}\right),\left(x^{*}, y^{*}\right)\right)\right) \leqslant s \widetilde{d}\left(\left(x_{n}, y_{n}\right),\left(F\left(x_{n}, y_{n}\right), F\left(y_{n}, x_{n}\right)\right)\right) .
$$

Since the mapping $\psi:[0, \infty) \rightarrow \mathbb{R}, \psi(t)=t-s \varphi(t)$, is such that $\psi(t) \geqslant 0, \forall t \in \mathbb{R}_{+}$and $\psi(0)=0$ implies that $t=0$, then, letting $n \rightarrow \infty$, we get that $\left(x_{n}, y_{n}\right) \rightarrow\left(x^{*}, y^{*}\right)$.

In what follows we shall give an Ulam-Hyers stability result for the coupled fixed point problem (P1).

Definition 3.3. Let $(X, d)$ be a complete b-metric space with constant $s \geqslant 1$, and let $\tilde{d}$ be any $b$-metric on $Z=X \times X$ generated by $d$. By definition, the coupled fixed point problem (P1) is said to be Ulam-Hyers stable if there exists $\psi: \mathbb{R}_{+} \rightarrow \mathbb{R}_{+}$, increasing, continuous in 0 with $\psi(0)=0$, such that for each $\varepsilon \in \mathbb{R}_{+}^{*}$ and for each solution $\left(u^{*}, v^{*}\right) \in X \times X$ of the inequality $\widetilde{d}((x, y),(F(x, y), F(y, x))) \leqslant \varepsilon$, there exists a solution $\left(x^{*}, y^{*}\right) \in X \times X$ of the coupled fixed point problem (P1) such that

$$
\widetilde{\mathrm{d}}\left(\left(\mathrm{x}^{*}, \mathrm{y}^{*}\right),\left(\mathrm{u}^{*}, v^{*}\right)\right) \leqslant \psi(\varepsilon) .
$$

Theorem 3.4. Assume that all the hypotheses of Theorem 2.7 take place. If the mapping $\gamma:[0, \infty) \rightarrow \mathbb{R}, \gamma(\mathrm{t})=$ $\mathrm{t}-\mathrm{s} \varphi(\mathrm{t})$ is such that $\gamma(\mathrm{t}) \geqslant 0, \forall \mathrm{t} \in \mathbb{R}_{+}$and $\gamma(0)=0$ implies that $\mathrm{t}=0$, then the coupled fixed point problem (P1) is Ulam-Hyers stable.

Proof. By Theorem 2.7 we get that $\mathrm{CFix}(\mathrm{F})=\left\{\left(\mathrm{x}^{*}, \mathrm{y}^{*}\right)\right\}$. Let $\varepsilon>0$ and let $\left(\mathrm{u}^{*}, v^{*}\right) \in X \times X$ such that $\tilde{\mathrm{d}}$ $\left(\left(\mathrm{u}^{*}, v^{*}\right),\left(\mathrm{F}\left(\mathrm{u}^{*}, v^{*}\right), \mathrm{F}\left(v^{*}, \mathrm{u}^{*}\right)\right)\right) \leqslant \varepsilon$ and $\left(\mathrm{x}^{*}, \mathrm{u}^{*}\right) \in \mathrm{E}(\mathrm{G}),\left(\mathrm{y}^{*}, v^{*}\right) \in \mathrm{E}\left(\mathrm{G}^{-1}\right)$.

Let $Z=X \times X$ and consider the functional $\widetilde{d}: Z \times Z \rightarrow[0, \infty)$ defined by

$$
\tilde{d}((x, y),(u, v))=d(x, u)+d(y, v) \text { for all }(x, y),(u, v) \in Z \text {. }
$$

We have

$$
\begin{aligned}
\widetilde{\mathrm{d}}\left(\left(\mathrm{u}^{*}, v^{*}\right),\left(x^{*}, \mathrm{y}^{*}\right)\right) & =\widetilde{\mathrm{d}}\left(\left(\mathrm{u}^{*}, v^{*}\right),\left(\mathrm{F}\left(\mathrm{x}^{*}, \mathrm{y}^{*}\right), \mathrm{F}\left(\mathrm{y}^{*}, \mathrm{x}^{*}\right)\right)\right) \\
& \leqslant s \widetilde{\mathrm{d}}\left(\left(\mathrm{u}^{*}, v^{*}\right),\left(\mathrm{F}\left(\mathrm{u}^{*}, v^{*}\right), \mathrm{F}\left(v^{*}, \mathrm{u}^{*}\right)\right)\right) \mathrm{s} \widetilde{\mathrm{d}}\left(\left(\mathrm{F}\left(\mathrm{u}^{*}, v^{*}\right), \mathrm{F}\left(v^{*}, \mathrm{u}^{*}\right)\right),\left(\mathrm{F}\left(\mathrm{x}^{*}, \mathrm{y}^{*}\right), \mathrm{F}\left(\mathrm{y}^{*}, \mathrm{x}^{*}\right)\right)\right) \\
& \leqslant s \varepsilon+s \varphi\left(\widetilde{\mathrm{d}}\left(\left(\mathrm{u}^{*}, v^{*}\right),\left(x^{*}, \mathrm{y}^{*}\right)\right)\right) .
\end{aligned}
$$

Hence

Thus we obtain that

$$
\widetilde{\mathrm{d}}\left(\left(\mathrm{u}^{*}, v^{*}\right),\left(x^{*}, \mathrm{y}^{*}\right)\right)-s \varphi\left(\widetilde{\mathrm{d}}\left(\left(\mathrm{u}^{*}, v^{*}\right),\left(x^{*}, \mathrm{y}^{*}\right)\right)\right) \leqslant s \varepsilon .
$$

where

$$
\widetilde{\mathrm{d}}\left(\left(\mathrm{u}^{*}, v^{*}\right),\left(x^{*}, \mathrm{y}^{*}\right)\right) \leqslant \psi(\varepsilon),
$$

$$
\psi(\varepsilon):=\sup \left\{t \in \mathbb{R}_{+} \mid t-s \varphi(t) \leqslant s \varepsilon\right\} .
$$

Since the mapping $\gamma:[0, \infty) \rightarrow \mathbb{R}, \gamma(t)=t-s \varphi(t)$ is such that $\gamma(t) \geqslant 0, \forall t \in \mathbb{R}_{+}$and $\gamma(0)=0$ implies that $t=0$, then the coupled fixed point problem (P1) is Ulam-Hyers stable. 


\section{Applications}

In what follows we shall give an application for Theorem 2.6. Let us consider the following problem:

$$
\left\{\begin{array}{rl}
x^{\prime \prime}(t) & =f(t, x(t), y(t)), \\
y^{\prime \prime}(t) & =f(t, y(t), x(t)), \\
x(0) & =x^{\prime}(1)=y(0)=y^{\prime}(1),
\end{array} \quad t \in[0,1] .\right.
$$

Notice now that the problem (4.1) is equivalent with the following integral system

$$
\left\{\begin{array}{l}
x(t)=\int_{0}^{1} K(t, s) f(s, x(s), y(s)) d s, \\
y(t)=\int_{0}^{1} K(s, t) f(s, y(s), x(s)) d s,
\end{array} \quad t 0,1\right],
$$

where

$$
K(t, s)= \begin{cases}t, & t \leqslant s \\ s, & t>s\end{cases}
$$

The purpose of this section is to give existence and uniqueness results for the solution of the system (4.2) using Theorem 2.6.

Let us consider $X:=C\left([0,1], \mathbb{R}^{n}\right)$ endowed with the following b-metric with $s=2$

$$
d(x, y)=\max _{t \in[0,1]}(x(t)-y(t))^{2} .
$$

Consider also the graph $\mathrm{G}$ defined by the partial order relation, i.e.,

$$
x, y \in X, x \leqslant y \Leftrightarrow x(t) \leqslant y(t) \text { for any } t \in[0,1] .
$$

Since $(X, \leqslant)$ is a lattice, we get that $(X, G)$ has the property $(2.3)$. Hence $(X, d)$ is a complete $b$-metric space endowed with a directed graph $\mathrm{G}$.

If we consider $E(G)=\{(x, y) \in X \times X: x \leqslant y\}$, then the diagonal $\Delta$ of $X \times X$ is included in $E(G)$. On the other hand $E\left(G^{-1}\right)=\{(x, y) \in X \times X: y \leqslant x\}$. Moreover $(X,\|\cdot\|, G)$ has the properties $\left(A_{1}\right)$ and $\left(A_{2}\right)$. In this case $(X \times X)^{F}=\{(x, y) \in X \times X: x \leqslant F(x, y)$ and $F(y, x) \leqslant y\}$.

Theorem 4.1. Consider the system (4.1). Suppose:

(i) $f:[0,1] \times \mathbb{R}^{\mathrm{n}} \times \mathbb{R}^{\mathrm{n}} \rightarrow \mathbb{R}^{\mathrm{n}}$ is continuous;

(ii) for all $x, y, u, v \in \mathbb{R}^{n}$ with $x \leqslant u, v \leqslant y$ we have $f(t, x, y) \leqslant f(t, u, v)$ for all $t \in[0,1]$;

(iii) there exists $\widetilde{\varphi}:[0, \infty) \rightarrow[0, \infty) a(b)$-comparison function and $\alpha, \beta \in(0, \infty)$, with $\max \{\alpha, \beta\}<1$, such that

$$
(f(t, x, y)-f(t, u, v))^{2} \leqslant \widetilde{\varphi}\left(\alpha(x-u)^{2}+\beta(y-v)^{2}\right) \text { for each } t \in[0,1], x, y, u, v \in \mathbb{R}^{n}, x \leqslant u, v \leqslant y ;
$$

(iv) there exists $\left(x_{0}, y_{0}\right) \in X \times X$ such that

$$
\left\{\begin{array}{l}
x_{0}(t) \leqslant \int_{0}^{1} K(t, s) f\left(s, x_{0}(s), y_{0}(s)\right) d s \\
y_{0}(t) \geqslant \int_{0}^{1} K(t, s) f\left(s, y_{0}(s), x_{0}(s)\right) d s \\
t \in[0,1] .
\end{array}\right.
$$


Then, there exists a unique solution of the integral system (4.2).

Proof. Let $\mathrm{F}: \mathrm{X} \times \mathrm{X} \rightarrow \mathrm{X},(\mathrm{X}, \mathrm{y}) \longmapsto \mathrm{F}(\mathrm{x}, \mathrm{y})$, where

$$
F(x, y)(t)=\int_{0}^{1} K(t, s) f(s, x(s), y(s)) d s, t \in[0,1]
$$

In this way, the system (4.2) can be written as

$$
\left\{\begin{array}{l}
x=F(x, y) \\
y=F(y, x)
\end{array}\right.
$$

It can be seen from (4.4), that a solution of this system is a coupled fixed point of the mapping F.

We shall verify if the conditions of Theorem 2.6 are fulfilled.

Let $x, y, u, v \in X$ such that $x \leqslant u$ and $v \leqslant y$. Using (ii), we have

$$
\begin{aligned}
& F(x, y)(t)=\int_{0}^{1} K(t, s) f(s, x(s), y(s)) d s \leqslant \int_{0}^{1} K(t, s) f(s, u(s), v(s)) d s=F(u, v)(t) \text { for each } t \in[0,1], \\
& F(v, u)(t)=\int_{0}^{1} K(t, s) f(s, v(s), u(s)) d s \leqslant \int_{0}^{1} K(t, s) f(s, y(s), x(s)) d s=F(y, x)(t) \text { for each } t \in[0,1] .
\end{aligned}
$$

Hence, if $x \leqslant u$ and $v \leqslant y$, then $F(x, y) \leqslant F(u, v)$ and $F(v, u) \leqslant F(y, x)$, which according to the definition of $E(G)$, it shows that $F$ is edge preserving. On the other hand, by Cauchy-Buniakovski-Schwarz inequality, we have

$$
\begin{aligned}
(F(x, y)(t)-F(u, v)(t))^{2} & \leqslant\left[\int_{0}^{1} K(t, s)(f(s, x(s), y(s))-f(s, u(s), v(s))) d s\right]^{2} \\
& \leqslant \int_{0}^{1} K^{2}(t, s) d s \int_{0}^{1}(f(s, x(s), y(s))-f(s, u(s), v(s)))^{2} \text { ds for each } t \in[0,1] .
\end{aligned}
$$

We have

$$
\int_{0}^{1} K^{2}(t, s) d s=\int_{0}^{t} s^{2} d s+\int_{t}^{1} t^{2} d s=t^{2}\left(1-\frac{2}{3} t\right) \leqslant \frac{1}{3} \text { for each } t \in[0,1] .
$$

Hence

$$
\begin{aligned}
(F(x, y)(t)-F(u, v)(t))^{2} & \leqslant \frac{1}{3} \int_{0}^{1}(f(s, x(s), y(s))-f(s, u(s), v(s)))^{2} d s \\
& \leqslant \frac{1}{3} \int_{0}^{1} \widetilde{\varphi}\left(\alpha(x(s)-u(s))^{2}+\beta(y(s)-v(s))^{2}\right) d s \\
& \leqslant \frac{1}{3} \widetilde{\varphi}(\alpha d(x, u)+\beta d(y, v)) \\
& \leqslant \frac{1}{3} \widetilde{\varphi}(\max \{\alpha, \beta\}(d(x, u)+d(y, v))) .
\end{aligned}
$$


Hence

$$
d(F(x, y), F(u, v)) \leqslant \frac{1}{3} \widetilde{\varphi}(\max \{\alpha, \beta\}(d(x, u)+d(y, v))), x \leqslant u, v \leqslant y .
$$

In a similar way, we obtain

$$
d(F(y, x), F(v, u)) \leqslant \frac{1}{3} \widetilde{\varphi}(\max \{\alpha, \beta\}(d(x, u)+d(y, v))), x \leqslant u, v \leqslant y .
$$

By (4.5) and (4.6) we have

$$
d(F(x, y), F(u, v))+d(F(y, x), F(v, u)) \leqslant \frac{2}{3} \widetilde{\varphi}(\max \{\alpha, \beta\}(d(x, u)+d(y, v))), x \leqslant u, v \leqslant y .
$$

Let us consider the function $\varphi:[0, \infty) \rightarrow[0, \infty), \varphi(t)=\frac{2}{3} \widetilde{\varphi}(k t), 0 \leqslant k<1$, which is a (b)-comparison function. Then, we have

$$
d(F(x, y), F(u, v))+d(F(y, x), F(v, u)) \leqslant \varphi(d(x, u)+d(y, v)), x \leqslant u, v \leqslant y .
$$

Thus we have that $F$ is a $(\varphi, G)$-contraction of type (b). Condition (iv) from Theorem 4.1 shows that there exists $\left(x_{0}, y_{0}\right) \in X \times X$ such that $x_{0} \leqslant F\left(x_{0}, y_{0}\right)$ and $F\left(y_{0}, x_{0}\right) \leqslant y_{0}$ which implies that $(X \times X)^{F} \neq \varnothing$.

On the other hand, because of (i) and of the fact that $(X,\|\cdot\|, G)$ has the properties $\left(A_{1}\right)$ and $\left(A_{2}\right)$ we have that either (i) or (ii) from Theorem 2.6 is fulfilled.

In this way, we have that $F: X \times X \rightarrow X$, defined by (4.3), verifies the conditions of Theorems 2.6 and 2.7. Thus, there exists $\left(x^{*}, y^{*}\right) \in X \times X$ which is a coupled fixed point of the mapping $F$ and, as a consequence, a solution of the problem (4.1).

\section{References}

[1] I. Beg, A. R. Butt, S. Radojević, The contraction principle for set valued mappings on a metric space with a graph, Comput. Math. Appl., 60 (2010), 1214-1219. 1

[2] V. Berinde, Generalized contractions in quasimetric spaces, Seminar on Fixed Point Theory, "Babe-Bolyai" Univ., Cluj-Napoca, (1993), 3-9. 1.2, 1.8

[3] V. Berinde, Sequences of operators and fixed points in quasimetric spaces, Studia Univ. Babeş-Bolyai Math., 41 (1996), 23-27. 1, 1.7

[4] V. Berinde, Contractii generalizate şi aplicaţii, (Romanian) [[Generalized contractions and applications]] Colecia Universitaria (Baia Mare) [University Collection], Editura Cub Press 22, Baia Mare, (1997). 1.5, 1, 1.6

[5] I. C. Chifu, G. Petruşel, Generalized contractions in metric spaces endowed with a graph, Fixed Point Theory Appl., 2012 (2012), 9 pages. 1

[6] I. C. Chifu, G. Petrussel, New results on coupled fixed point theory in metric spaces endowed with a directed graph, Fixed Point Theory Appl., 2014 (2014), 13 pages. 1, 1.10, 1.11, 1.12, 1.13, 2.1

[7] S. Czerwik, Nonlinear set-valued contraction mappings in b-metric spaces, Atti Sem. Mat. Fis. Univ. Modena, 46 (1998), 263-276. 1.1

[8] T. Gnana Bhaskar, V. Lakshmikantham, Fixed point theorems in partially ordered metric spaces and applications, Nonlinear Anal., 65 (2006), 1379-1393. 1

[9] G. Gwóźdź-Łukawska, J. Jachymski, IFS on a metric space with a graph structure and extensions of the Kelisky-Rivlin theorem, J. Math. Anal. Appl., 356 (2009), 453-463. 1

[10] J. Harjani, K. Sadarangani, Fixed point theorems for weakly contractive mappings in partially ordered sets, Nonlinear Anal., 71 (2009), 3403-3410. 1

[11] J. Jachymski, The contraction principle for mappings on a metric space with a graph, Proc. Amer. Math. Soc., 136 (2008), 1359-1373. 1

[12] J. Jachymski, J. Klima, Around Perov's fixed point theorem for mappings on generalized metric spaces, Fixed Point Theory, 17 (2016), 367-380. 2.12

[13] M. Jleli, B. Samet, C. Vetro, F. Vetro, Fixed points for multivalued mappings in b-metric spaces, Abstr. Appl. Anal., 2015 (2015), 7 pages. 1

[14] J. J. Nieto, R. Rodríguez-López, Contractive mapping theorems in partially ordered sets and applications to ordinary differential equations, Order, 22 (2005), 223-239. 1

[15] J. J. Nieto, R. L. Pouso, R. Rodríguez-López, Fixed point theorems in ordered abstract spaces, Proc. Amer. Math. Soc., 135 (2007), 2505-2517. 1 
[16] J. J. Nieto, R. Rodríguez-López, Existence and uniqueness of fixed point in partially ordered sets and applications to ordinary differential equations, Acta Math. Sin. (Engl. Ser.), 23 (2007), 2205-2212. 1

[17] D. O’Regan, A. Petruşel, Fixed point theorems for generalized contractions in ordered metric spaces, J. Math. Anal. Appl., 341 (2008), 1241-1252. 1

[18] A. C. M. Ran, M. C. B. Reurings, A fixed point theorem in partially ordered sets and some applications to matrix equations, Proc. Amer. Math. Soc., 132 (2004), 1435-1443. 1

[19] C. Vetro, F. Vetro, Metric or partial metric spaces endowed with a finite number of graphs: a tool to obtain fixed point results, Topology Appl., 164 (2014), 125-137. 1 